\title{
EFFECT OF COCONUT SHELL ASH (CSA) AS AN ADMIXTURE ON THE PROPERTIES OF CEMENT PASTE AND CONCRETE
}

\author{
Ravi Goutam, Gajendra Meghwal, Yogesh Kumar Rawat, Devendra Sharma \\ E-Mail Id: ravigoutam248@gmail.com \\ Department of Civil Engineering, AITS, Udaipur, India
}

\begin{abstract}
Concrete is the most important construction material. It is used in all type of construction works like infrastructure-, low- and high-rise building and domestic developments. It is man-made product. It is mixture of cement, aggregate, water and admixture. Sand, crushed stone, gravel are aggregates. Mainly aggregates are available natural resources. Taking of aggregates from natural resources affect the environment. In the modern world we use many alternatives of aggregates like waste material and industry products such as fly ash, bottom ash, recycled aggregates, foundry sand, and glass. Apart from above few studies identified that the coconut shell can also be used as aggregate in concrete. Coconut is grown in 86 countries. India has a good position in world for production of coconut.
\end{abstract}

Keywords: Fly ash, bottom ash, coconut shell ash, admixture.

\section{INTRODUCTION}

The goal of this study is to assess the utility and efficacy of coconut shells as a coarse aggregate as an another natural aggregate in concrete Coconut shells have not been attempted as total in underlying cement.Practically all over the world various goals at reducing the use of main aggregates and increasing reuse and recycling have been introduced, where it is technically, economically, or environmentally allowable As a result, in growing countries like India, the unofficial sector and secondary industries recycle $15-20 \%$ of solid wastes in various building materials and components.

Coconut shells have good durability quality, high toughness and abrasion resistant characteristic; it is suitable for large use. Coconut shells are used in ornament, making fancy items, house hold instrument, and as a source of activated carbon from its charcoal. The powdered shell is also used in the industries of plastics, glues, and grinding materials. It is widely used for the manufacture of insect repellent in the form of mosquito coils The motivation behind this examination work is to build up a solid with coconut shells as coarse total.

\section{OBJECTIVES OF THE RESEARCH}

If low weight concrete can be developed from coconut shells, which is locally available in high quantity, it would be a big achievement for the local construction industries. Therefore, the main objective of this research is to 8 determine the feasibility of using solid waste coconut shells as coarse aggregate for structural low weight concrete. The research objectives are briefly summarized below.

$>$ To examine the properties of coconut shells, similarity of coconut shells with concrete and to create coconut shell total cement with multi day compressive strength in excess of $20 \mathrm{~N} / \mathrm{mm} 2$.

$>$ To examine the strength properties of cement in substitution of coarse total.

$>$ To contemplate the conduct of compressive and split elasticqualities.

\section{METHODOLOGY}

The properties of coconut shell such as chemical, physical, mechanical, and the compatibility of coconut shell with cement were study. Production of low weight concrete with follow standard procedures and methods. The various trial mixes work conducted by varying cement content, sand, coconut shells, and water cement ratio.

The acceptable trial mixes were then identified and finally, the workability, strength, density and durability requirements for different applications of low weight concrete were taken into consideration during the selection of the optimum coconut shell aggregate concrete mix. The concrete mix was optimized for coconut shells cement ratio and water cement ratio. Such as flexural and shear behavior of reinforced coconut shell aggregate concrete beams were studied by making prototype elements. the results are compared with the other low weight aggregate used in concrete. Correlations of certain properties for coconut shell total cement were made utilizing a few codes of training. Tests led on temperature attributes of coconut shell total cement are examined.

\section{EXPERIMENTAL INVESTIGATION}

\subsection{Materials}

The constituent materials utilized in this examination were obtained from neighborhood sources. These materials are needed by directing different tests. Because of these outcomes we characterized what kind of materials are to be utilized. Due to these results, we defined what type of materials are to be used. We are using cement, fly ash, coarse aggregate, fine aggregate, coconut shells and water. 


\subsection{Cement}

Common Portland concrete of C53 grade adjusting to both the necessities of IS: 12269 and ASTM C 642-82 sort I was utilized. We directed various sorts of tests on concrete, those are Normal Consistency, Initial and Final setting times, Compressive strength of concrete, Specific Gravity and Fineness of concrete.

\subsection{Coarse Aggregate}

Ordinary total that is squashed blue stone of greatest size $20 \mathrm{~mm}$ was utilized as coarse total. We are directing tests on coarse total are water absorption capacity, specific gravity.

\subsection{Fine Aggregate}

All around evaluated stream sand going through $4.75 \mathrm{~mm}$ was utilized as fine total. The sand was air-dried and sieved to remove any foreign particles prior to mixing. We are directing tests on fine total are water absorption capacity, specific gravity and fineness modulus of fine total.

\subsection{Fly Ash}

Fly debris intently takes after volcanic cinders utilized underway of the most punctual known hydraulic cements about 2,300 years ago. Those cements were made near the small Italian town of Pozzuoli - which later gave its name to the term pozzolan. A pozzolan is siliceous/aluminous material that, when mixed with lime and water, forms a cementitious compound. Fly ash is the best known, and one of the most commonly used, pozzolans in the world. Types of Fly ash:
$>$ Class F fly ash
$>$ Class C fly ash

\subsection{Coconut Shell}

The coconut palm is one of the most useful plants in the world. Coconut is grown in 92 countries in the world. Global production of coconut is 51 billion nuts from an area of 12 million hectares. Coconut shells which were already broken into two pieces were collected from local temple; air dried for five days approximately at the temperature of 25 to $30 \mathrm{C}$; water absorption of the coconut shells was $8 \%$ and specific gravity at saturated surface dry condition of the material.

\subsection{Water}

The quality of water is important because contaminants can adversely affect the strength of concrete and cause corrosion of the steel reinforcement. Water used for producing and curing concrete should be reasonably clean and free from deleterious substances such as oil, acid, alkali, salt, sugar, silt, organic matter and other elements which are detrimental to the concrete or steel. If the water is drinkable, it is considered to be suitable for concrete making. Hence, potable tap water was used in this study for mixing and curing. fine particles passing through IS sieve 9, IS sieve 15 , IS sieve 30 were taken and analyzed without any treatment.

\section{DISCUSSION}

\subsection{Mix Proportion}

Blend configuration is the way toward choosing an ideal extent of concrete, fine and coarse totals and water to create a solid with indicated properties of functionality, strength, and solidness. The best mix involves a balance between economy and the required properties of concrete.To explore properties of coconut shells cements, five blends were utilized. Control blend (M1) that is, without coconut shells was made. Coarse total was then supplanted with coconut shells in 10 (M2), 20 (M3), rates to examine impact of CS substitution.

\subsection{Water Cement Ratio (W/C)}

It is hard to indicate the ideal w/c proportion for a wide range of wood concrete composite. Thus, it is important to advance the coconut shells total - concrete proportion and w/c proportion. It is seen that with the expansion of w/c proportion, the strength of coconut shell total cement diminished. In this way w/c proportion was considered as 0.38 , 0.42 , and 0.45 .

Adequate water sum is the essential for top notch concrete based items. Notwithstanding, on the grounds that water can build the distance between concrete particles previously and during hydration, and increment the volume of slim pores, for example the porosity of the hydrated items, abundance water may antagonistically influence the physicalmechanical properties of the hydrated items.

\subsection{Coconut Shell Aggregate Concrete (CSAC):}

Writing shows that when wood based materials are utilized as total in concrete, the organic disintegration isn't clear. Coconut shells total has nearly high water assimilation qualities. Accordingly, to keep away from water assimilation during the blending cycle, it is crucial for blend coconut shells total at SSD condition dependent on $24 \mathrm{~h}$ submersion in consumable water. It is focused to create coconut shell total cement of compressive strength in excess of $17 \mathrm{~N} / \mathrm{mm} 2$ to meet the base strength of primary concrete according to ASTM C330. It is focused to deliver coconut shell total 
SCRDSI-2021, Aravali Institute of Technical Studies, Udaipur (Rajasthan), India

International Journal of Technical Research \& Science (Special Issue) ISSN No.:2454-2024 (online)

cement of compressive strength in excess of $17 \mathrm{~N} / \mathrm{mm} 2$ to meet the base strength of underlying concrete according to ASTM C 330.

However, according to IS 456:2000, the base strength of underlying cement is in excess of $20 \mathrm{~N} / \mathrm{mm} 2$ and this was additionally considered to deliver coconut shell total cement. Blend configuration is the way toward choosing an ideal extent of concrete, fine and coarse totals and water to create a solid with determined properties of usefulness, strength, and toughness. The best blend includes a harmony among economy and the necessary properties of cement.

\subsection{Curing}

The goal of restoring is to keep concrete immersed or as almost soaked to get the results of hydration of concrete in water-occupied space. The temperature of restoring and the length of clammy relieving are the vital components for legitimate restoring.

The damp restored tests invigorate higher compressive than dry relieved examples of cement with specific admixtures. In a wide range of relieving the strength of cement is needy somewhat upon the strength of total. The augmentation rate in strength is more in squashed stone cement than in OPS concrete.

\section{CONCLUSIONS}

Results of experiments on compressive strength, split tensile strength, water absorption and sorption for different coconut shells replaced concretes have been presented with those of control concrete. However, performance of coconut shells aggregate concrete having a marginal variation than normal aggregate concrete. The main points of this study are:

$>$ Addition of coconut shells decreases workability and addition of fly ash as cement replacement increases workability of coconut shells concrete. Increase in coconut shells percentage decreased densities of the concretes.

$>$ By replacement of coconut shells in place of aggregates, $10 \%$ \&20\% replacement will have been decreased marginally the strength properties of concrete compared to the normal concrete.

$>$ But the replacement of coconut shells in place of aggregates and replacement of fly ash in place of cement will increase the strength properties of concrete compared to the normal concrete.

$>\quad$ The replacement of the $10 \%$ coconut shells as coarse aggregate will decrease the marginal value of $2.88 \%$ in compression and $2.7 \%$ in split tensile strength.

$>$ The replacement of the $20 \%$ coconut shells as coarse aggregate will decrease the marginal value of $8.39 \%$ in compression and $10.25 \%$ in split tensile strength.

$>$ The replacement of the $10 \%$ coconut shells as coarse aggregate and $10 \%$ fly ash as cement will decreases the marginal value of $0.525 \%$ in compression and increase of $4.05 \%$ in split tensile strength.

$>\quad$ The replacement of the $10 \%$ coconut shells as coarse aggregate and $10 \%$ fly ash as cement decreases the marginal value of $0.205 \%$ in compression and increase of $2.7 \%$ in split tensile strength.

Coconut shell as coarse aggregate and Fly ash as cement will increase the compressive strength of concrete.

\section{REFERENCES}

[1] DewanshuAhlaw and L.G.Kalurkar, "Strength Properties of Coconut Shell Concrete," International Journal of Civil Engineering \& Technology (IJCIET), Volume 4, Issue 7, 2012, pp. 20 - 24, ISSN Print: 0976 6308, ISSN Online: $0976-6316$.

[2] M.R. Kolhe and Dr. P.G. Khot, "Utilization Of Natural Resources With Due Regards To Conservation/Efficiency or Both”, International Journal of Management (IJM), Volume 5, Issue 12, 2014, pp. 1 - 11, ISSN Print: 0976-6502, ISSN Online: 0976-6510.

[3] Torgal,F.P, Jalali, Said,"Compressive strength and durability proper-ties of ceramic wastes based concrete”, Materials and structures,no. 44 (2011): 155-167.

[4] American society for testing and materials (ASTM) C-125 (2007). Saturated terminology relating to concrete and concrete aggregate; 2007. 